\title{
Article
}

\section{Antifungal Carvacrol Loaded Chitosan Nanoparticles}

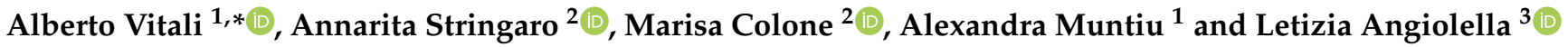 \\ 1 Istituto di Scienze e Tecnologie Chimiche "Giulio Natta", Consiglio Nazionale delle Ricerche, L. go F. Vito 1, \\ 00168 Rome, Italy; alexandra.muntiu@gmail.com \\ 2 National Center for Drug Research and Evaluation, Italian National Institute of Health, V. le Regina Elena, \\ 299, 00161 Rome, Italy; annarita.stringaro@iss.it (A.S.); marisa.colone@iss.it (M.C.) \\ 3 Department of Public Health and Infectious Diseases, "Sapienza" University of Rome, P. le Aldo Moro, 5, \\ 00185 Rome, Italy; letizia.angiolella@uniroma1.it \\ * Correspondence: alberto.vitali@scitec.cnr.it
}

check for updates

Citation: Vitali, A.; Stringaro, A.; Colone, M.; Muntiu, A.; Angiolella, L. Antifungal Carvacrol Loaded Chitosan Nanoparticles. Antibiotics 2022, 11, 11. https://doi.org/ 10.3390/antibiotics11010011 Academic Editor: Raymond J. Turner Received: 27 November 2021 Accepted: 22 December 2021 Published: 22 December 2021 Publisher's Note: MDPI stays neutral with regard to jurisdictional claims in published maps and institutional affiliations.

Copyright: (C) 2021 by the authors. Licensee MDPI, Basel, Switzerland. This article is an open access article distributed under the terms and conditions of the Creative Commons Attribution (CC BY) license (https:// creativecommons.org/licenses/by/ $4.0 /)$.

\begin{abstract}
The increased prevalence and incidence of fungal infections, of which Candida albicans represents one of the most life-threatening organisms, is prompting the scientific community to develop novel antifungal molecules. Many essential oils components are attracting attention for their interesting antifungal activities. Given the chemical and physical characteristics of these compounds, the use of appropriate nanodelivery systems is becoming increasingly widespread. In this study, chitosan nanoparticles were prepared using an ionic gelation procedure and loaded with the phenolic monoterpene carvacrol. After a bioassay guided optimization, the best nanoparticle formulation was structurally characterized by means of different spectroscopic (UV, FTIR and DLS) and microscopy techniques (SEM) and described for their functional features (encapsulation efficiency, loading capacity and release kinetics). The antifungal activity of this formulation was assayed with different Candida spp., both in planktonic and biofilm forms. From these studies, it emerged that the carvacrol loaded nanoparticles were particularly active against planktonic forms and that the antibiofilm activity was highly dependent on the species tested, with the C. tropicalis and C. krusei strains resulting as the most susceptible.
\end{abstract}

Keywords: carvacrol; chitosan; nanoparticles; Candida; antifungal; biofilm

\section{Introduction}

Essential oils (EO) have widespread uses in the health, agricultural, food, cosmetic and pharmaceutical industries due to their potent antimicrobial activities. Many single components of the EO maintain the antimicrobial potency of the whole oil mixture. Various examples are also reported in which EOs single components were delivered in different nano-systems [1]. Carvacrol $(\mathrm{Cv})$, a monoterpene phenol and one of the main components of oregano (Origanum vulgare) EO [2], features many interesting biological properties [3]. Known as a food preservative, it also possesses potent antioxidant activities comparable to those of ascorbic acid and vitamin E [4]. Carvacrol is a potent antimicrobial agent against molds and Gram-positive and Gram-negative bacteria. Its antimicrobial activities were tested in different studies [5]. In particular, its antifungal action was evaluated against human pathogens such as Candida spp. [6,7] and Malassezia spp. [8,9] showing remarkable efficacy. In a recent study, carvacrol treatment was shown to cause permeability and depolarization of the cell membrane of Candida albicans cells. In addition, after carvacrol treatment, apoptosis-related markers (DNA fragmentation and metacaspase activation) were observed, and total and mitochondrial reactive oxygen species (ROS) levels were increased, as long as the cytosolic and mitochondrial calcium levels did. Furthermore, carvacrol was shown to have low toxicity and to be effective in alleviating systemic C. albicans infections through its antifungal and immunomodulatory activities [10]. The chemical structure of carvacrol makes this compound a volatile molecule at room temperature, with an almost complete lack of idrosolubility. Furthermore, carvacrol at high concentrations 
may be toxic to many cells [11]. Thus, to enhance carvacrol bioavailability and stability, while at the same time limiting potential negative side-effects, different nano-formulations have been proposed for its delivery to be applied as food preservative [12-14] or to contrast bacterial strains $[15,16]$. Chitosan (Cs), a polymer obtained for deacetylation of the natural compound chitin, is greatly consolidated in nano- and micro-delivery applications, due to its characteristics of biocompatibility, biodegradability, low toxicity, and high hydrophilicity $[17,18]$, and because of the relative ease in preparing nano or microparticles [19,20]. Moreover, it can be used to prepare films, membranes, gels, beads, fibers [21,22]. Cs is widely used in the preparation of antimicrobial nanodevices for its intrinsic antibacterial properties against Gram-positive and Gram-negative bacteria and towards fungal pathogens [23,24]. Different kinds of molecules (small molecules, peptides, nucleic acids) may be administered through mucous membranes thanks to the ability of $\mathrm{Cs}$ to stimulate transient opening of the tight junctions of the cell membrane. It is available in different size preparations from low to high molecular weights, allowing a fine-tuning of the nanoor micro-particles dimensions. High molecular weight chitosans are generally less soluble in water; conversely, low molecular wight $C$ s are more hydrosoluble and easier to manipulate for the production of nanoparticles. Additionally, the presence of free amino groups renders the Cs nanodevice prone to be functionalized with other molecules, for example antimicrobial peptides [25] cell-penetrating peptides (CPPs) [26] or tumor homing peptides [27] for a targeted and highly specific delivery of the desired drugs.

Candida spp. are among the most frequent nosocomial pathogens, contributing significantly to morbidity and mortality of hospitalized patients. Candida albicans was the most prevalent species (50.7\%), followed by Candida parapsilosis (17.4\%), Candida glabrata (16.7\%) and Candida tropicalis (10.2\%). The prevalence of non-albicans Candida spp. increased over time [28]. A major virulence attribute of Candida albicans is in fact related to its ability to form biofilms, densely packed communities of cells intrinsically resistant to conventional antifungal therapeutics, the host immune system, and other environmental factors, making biofilm-associated infections a significant clinical challenge [29]. Biofilm formation, although being a process present in all the Candida species focused above, differs significantly from species to species, and in the dependency of surface, host niche and other factors. Biofilm characteristics depend on the ability of each species to produce extracellular polymeric substances (EPS) and display dimorphic growth, but also on the biofilm substratum, carbon source availability and other factors [30].

In this study we have explored the possibility to couple the antifungal properties of $\mathrm{Cs}$ and $\mathrm{Cv}$, preparing nanoparticles based on low molecular weight $\mathrm{Cs}$ and testing their efficiency towards different strains of Candida. After a bioassay guided optimization for the preparation of efficient $\mathrm{Cv}$ loaded nanoparticles, the final formulation composed of a Cs/Cv 1:1.5 $(w / w)$ ratio, was characterized by UV spectrophotometry, attenuated total reflectance-Fourier transform infrared spectroscopy (ATR-FTIR), scanning electron microscopy (SEM), dynamic light scattering (DLS). Encapsulation efficiency (EE) and loading capacity (LC) were also evaluated as long with the release kinetic. To evaluate the antifungal properties of the so prepared carvacrol-loaded chitosan nanoparticles, they were challenged with Candida albicans, Candida krusei, Candida glabrata and Candida tropicalis strains both in planktonic and biofilm forms.

MIC values, killing kinetics and effects on pre-formed and established biofilm have been also evaluated.

\section{Results and Discussion}

\subsection{NPs Preparation}

Empty chitosan nanoparticles (Cs-NPs) loaded with carvacrol (Cv-Cs-NPs), were prepared as reported in the Materials and Methods (Section 3) following an ionotropic gelation-based procedure. In order to determine the formation of carvacrol-loaded chitosan nanoparticles the $\mathrm{Cv}$ loaded nanoparticles obtained with different $\mathrm{Cs} / \mathrm{Cv}$ ratios were analyzed firstly by UV-VIS spectrophotometry. 
The maximum absorption peak of the carvacrol-ethanol solution is at $275 \mathrm{~nm}$, as reported elsewhere [31]. The supernatant of chitosan particles immersed in ethanol for $1 \mathrm{~h}$ showed no absorption peak at wavelengths between 240 and $350 \mathrm{~nm}$. On the other hand, the obtained solution containing loaded NPs after centrifugation showed a maximum absorption peak at $275 \mathrm{~nm}$, clearly indicating the presence of carvacrol and consequently, its loading into chitosan particles.

\subsection{Bioassay Guided Nanoparticles Optimization}

In a first set of the experiments aimed to optimize the antifungal effect of different $\mathrm{Cs} / \mathrm{Cv}$ formulations, we assayed the antimicrobial activity of chitosan nanoparticles loaded with different amounts of carvacrol against C. albicans AIDS 68 strain taken as reference. In Table 1 are reported the obtained results. The data shown that the MICs were about $>2400 \mu \mathrm{g} / \mathrm{mL}$ for all the nanoparticles characterized by a $w / w$ ratio in favor of Cs. NPs produced with a $1: 1(\mathrm{Cs} / \mathrm{Cv}, w / w)$ ratio showed an antifungal activity identical to that of free Cv (MIC $1200 \mu \mathrm{g} / \mathrm{mL}$ ). An enhancement in the antifungal activity could be achieved augmenting the $\mathrm{Cs} / \mathrm{Cv}$ in favor of $\mathrm{Cv}$, with a dramatic effect obtained when carvacrol was loaded in a ratio of 1:1.50 (Cs/Cv, w/w), with a resulting MIC of $24 \mu \mathrm{g} / \mathrm{mL}$ (Table 2). Interestingly, this value resulted highly lower respect free $\mathrm{Cv}$ indicating a good loading efficiency of this formulation. In particular, a dramatic difference could be observed between the 1:1.25 and 1:1.5 ratios. Such a difference in the effect given by the two formulations is difficult to interpret. As observed in many biological systems such an effect is probably due to the complexity in the response of the biological system itself to loaded nanoparticles as reported by Bell and coll. [32].

Table 1. Antimicrobial activities of NPs obtained with different Cs/Cv loaded in Cs-NPs C. albicans against AIDS 68.

\begin{tabular}{ccc}
\hline Material & Cs/Cv $(w / w)$ & MIC $\mu \mathrm{g} / \mathrm{mL}$ \\
\hline Cs & - & $>2400$ \\
\hline Cv & - & 1200 \\
\hline Cs-NPs & - & 1580 \\
\hline Cv-Cs NPs & $1: 0.25$ & $>2400$ \\
\hline Cv-Cs-NPs & $1: 0.50$ & $>2400$ \\
\hline Cv-Cs-NPs & $1: 0.75$ & $>2400$ \\
\hline Cv-Cs-NPs & $1: 1$ & $>2400$ \\
\hline Cv-Cs-NPs & $1: 1.25$ & 1200 \\
\hline Cv-Cs-NPs & $1: 1.50$ & 24 \\
\hline
\end{tabular}

Consequently, this formulation, was used for all the following experiments to test the antimicrobial and antibiofilm activity against different Candida species.

\subsection{Cs-Cv-NPs Characterization}

In order to characterize the $\mathrm{Cv}-\mathrm{Cs}-\mathrm{NPs}$ obtained from the optimization rounds, different analytical techniques have been employed. After the UV analysis to confirm the presence of $\mathrm{CV}$, a further characterization of $\mathrm{CV}-\mathrm{Cs}-\mathrm{NPs}$ was made by means of ATR- FT-IR analysis. Although the spectra of the products obtained with the addition of carvacrol are similar to that of the chitosan particles, the intensity of the $\mathrm{CH}$ stretching peak at $2870-2960 \mathrm{~cm}^{-1}$ increases significantly, indicating the presence of carvacrol in the chitosan matrix, as reported in Figure 1. Similar signals have been obtained in other studies relating to carvacrol encapsulation in chitosan nanoparticles [33] confirming our data on the successful incorporation of the monoterpene in Cv-Cs-NPs. 


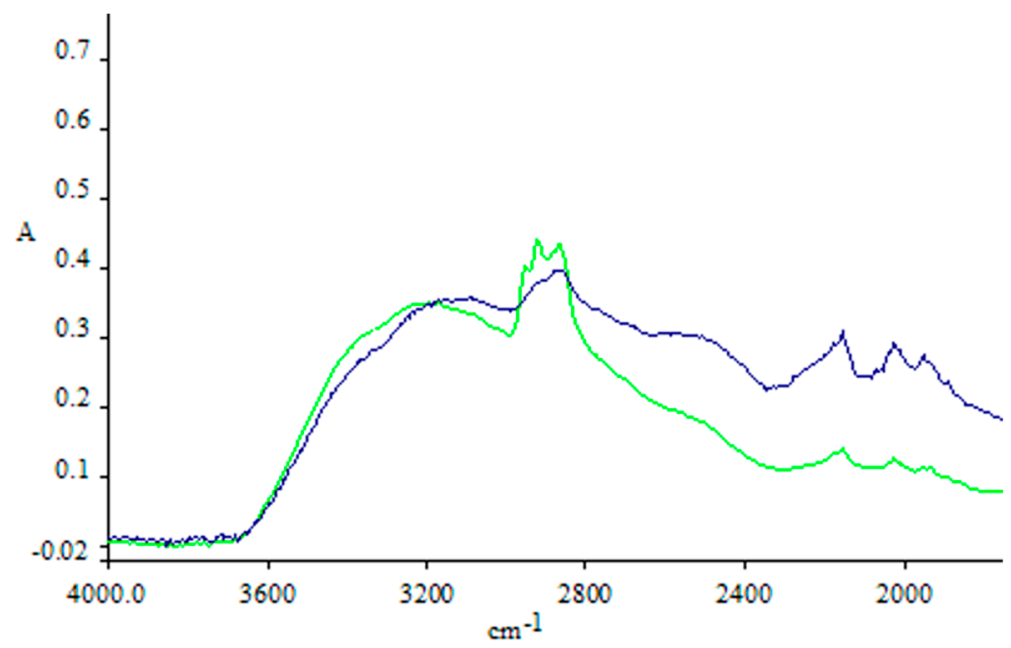

Figure 1. ATR-FTIR spectra of Cs-NPs Chitosan (blue line) and Cv-Cs-NPs (green line).

The morphology of empty chitosan Cs-NPs and Cv-Cs-NPs were observed by scanning electron microscopy (SEM), with both showing a spherical shape. As is evident from the image (Figure 2a,b), the nanoparticles are in a high aggregated state due to the air dehydrated environment used to prepare SEM samples. This is also not surprising given their size in the range of $150-400 \mathrm{~nm}$ and the fact that the preparation process chosen was $\mathrm{O} / \mathrm{A}$ emulsion.
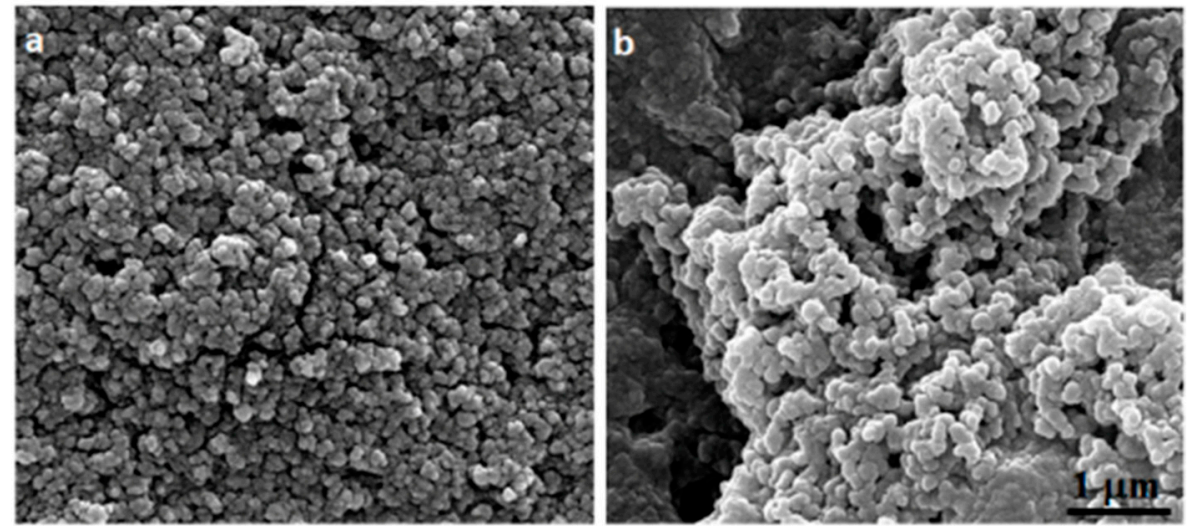

Figure 2. SEM images of empty chitosan NPs (a) and carvacrol-loaded nanoparticles (b).

Furthermore, similar morphology and aggregation patterns were observed in different studies concerning the preparation of chitosan nanoparticles [34,35].

The average dimensions in terms of hydrodynamic radius of the particles, was investigated by means of dynamic light scattering (DLS) technique. The average dimensions of obtained Cs-NPs and Cv-Cs-NPs were above the canonical $100 \mathrm{~nm}$ to be considered nanoparticles, however in the biomedical field the size range of NPs was extended to $1000 \mathrm{~nm}$. The empty chitosan nanoparticles and the loaded carvacrol nanoparticles showed a hydrodynamic diameter of 384.5 and $281.6 \mathrm{~nm}$ respectively (Table 2) in accordance with other studies involving the encapsulation of $\mathrm{Cv}$ [32] and other phenolic compounds characterized by similar dimensions of carvacrol [36-38]. The empty chitosan particles and the Cv-Cs-NPs yielded similar PDI values of 0.235 and 0.2475 respectively (Table 1 ) indicating an acceptable grade of monodispersity [39]. 
Table 2. Size and surface charge parameters of Cs-NPs and Cv-Cs-NPs in PBS buffer. Values are reported as mean $\pm \mathrm{SEM}, \mathrm{n}=3$.

\begin{tabular}{ccc}
\hline & Cv-Cs-NP & Cs-NP \\
\hline Hydrodynamic diameter $(\mathrm{nm})$ & $281.6 \pm 2$ & $384.5 \pm 3$ \\
\hline Polydispersity index $(\mathrm{PdI})$ & $0.235 \pm 0.03$ & $0.2475 \pm 0.02$ \\
\hline
\end{tabular}

The encapsulation efficiency (EE), loading capacity (LC) and the release kinetic of $\mathrm{Cv}$ were also evaluated. The nanoparticles obtained by mixing $C s$ and $C v$ in a 1:1.5 (w/w) showed percentages of $56 \%$ of EE and a $25.5 \%$ of LC calculated respectively using the Equations (1) and (2) as reported in the Materials and Methods (Section 3).

The timing of carvacrol release from nanoparticles was observed using a buffer solution at $\mathrm{pH}$ 7. The study was carried out for 5 days, taking samples at different incubation time checkpoints $(0,24,48,72$, and $96 \mathrm{~h})$. The amount of carvacrol released in the supernatant was calculated by reading the UV absorption at $275 \mathrm{~nm}$.

The release of carvacrol from the chitosan-carvacrol particles at $37^{\circ} \mathrm{C}$ was followed for five days and resulted to be very fast in the first two days when $42 \%$ of cumulative release of $\mathrm{Cv}$ was calculated, after which a slow release could be observed (Figure 3). Similar behavior was observed for released chlorogenic acid [38] and ciprofloxacin [40] chitosan nanoparticles in similar $\mathrm{pH}$ conditions.

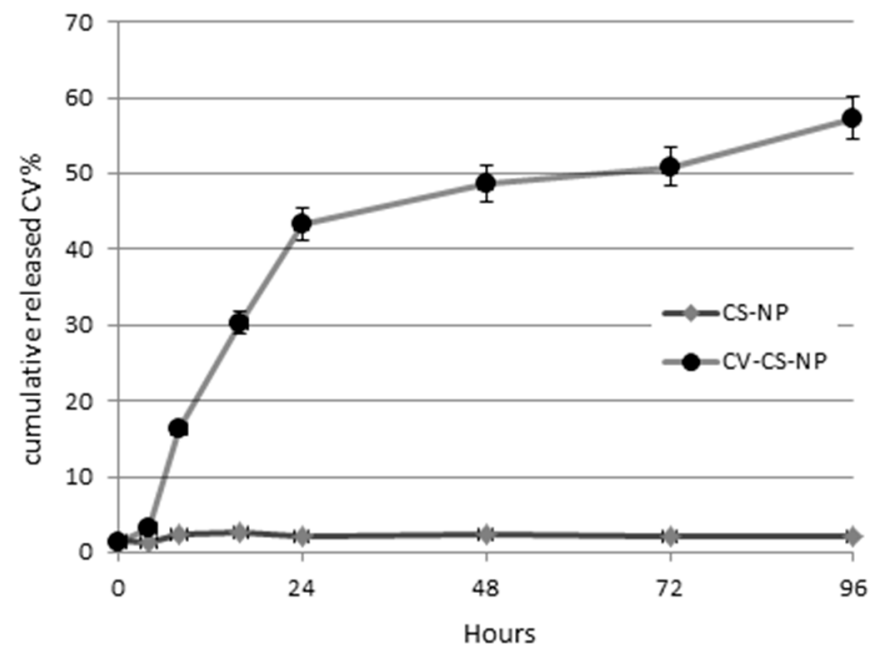

Figure 3. Kinetic of cumulative $\mathrm{Cv}$ release at $\mathrm{pH} 7.4$ at $37^{\circ} \mathrm{C}$ in five days from $\mathrm{Cv}-\mathrm{Cs}-\mathrm{NPs}$ prepared with a Cs/Cv 1:1.5 (w/w) ratio. Results are reported as mean $\pm \mathrm{SD}, \mathrm{n}=3$.

\subsection{Evaluation of Antimicrobial Activity}

In all the following experiments freshly prepared Cs-NP and $\mathrm{Cv}-\mathrm{Cs}-\mathrm{NPs}$ were prepared to avoid loss of efficacy. The antimicrobial activity of $\mathrm{Cv}$-Cs-NPs was tested on four Candida spp., specifically C. albicans AIDS 68, C. glabrata SFY115, C. tropicalis 47829 and C. krusei 45709 (Table 3).

Table 3. MIC Antimicrobial activity of chitosan-carvacrol nanoparticles (CV-CS NPs) against Candida spp. The concentrations of the different compounds are expressed as $\mu \mathrm{g} / \mathrm{mL}$.

\begin{tabular}{ccccc}
\hline Strains & Cs & Cv & Cs-NPs & Cv-Cs-NPs 1:1.50 \\
\hline C. albicans AIDS68 & 1560 & 780 & 1560 & 24 \\
C. tropicalis 47829 & $>3120$ & 780 & 3120 & 1560 \\
C. krusei 45709 & 1560 & 780 & 3120 & 1560 \\
C. glabrata SFY115 & 1560 & 780 & 1560 & 780 \\
\hline
\end{tabular}


The MIC values for free $\mathrm{Cv}$ are the same for all the strains assayed, while a marked difference was shown for $\mathrm{Cv}-\mathrm{Cs}_{-} \mathrm{NPs}$. In this case the lowest MIC value $(24 \mu \mathrm{g} / \mathrm{mL})$ was obtained only in C. albicans, while for the other strains it ranged from $780 \mu \mathrm{g} / \mathrm{mL}$ to $1560 \mu \mathrm{g} / \mathrm{mL}$. These results may account for a specie-specific dependent mode of action of these NPs. Similar results were reported by other authors with green synthesis of silver nanoparticles [41]. On the other side, free Cs and Cs-NPs showed MIC values generally higher respect $\mathrm{Cv}$ and $\mathrm{Cv}-\mathrm{Cs}-\mathrm{NPs}$, although a species dependent mode of action could be observed.

To assess the kinetics of the killing effect of $\mathrm{Cv}-\mathrm{Cs}-\mathrm{NPs}$, time-killing experiments were carried out on C. albicans, C. glabrata, C. krusei and C. tropicalis strains with Cv-Cs-NPs, Cs-NPs, Cv, Cs alone at the respective MIC concentrations (Figure 4A-D).
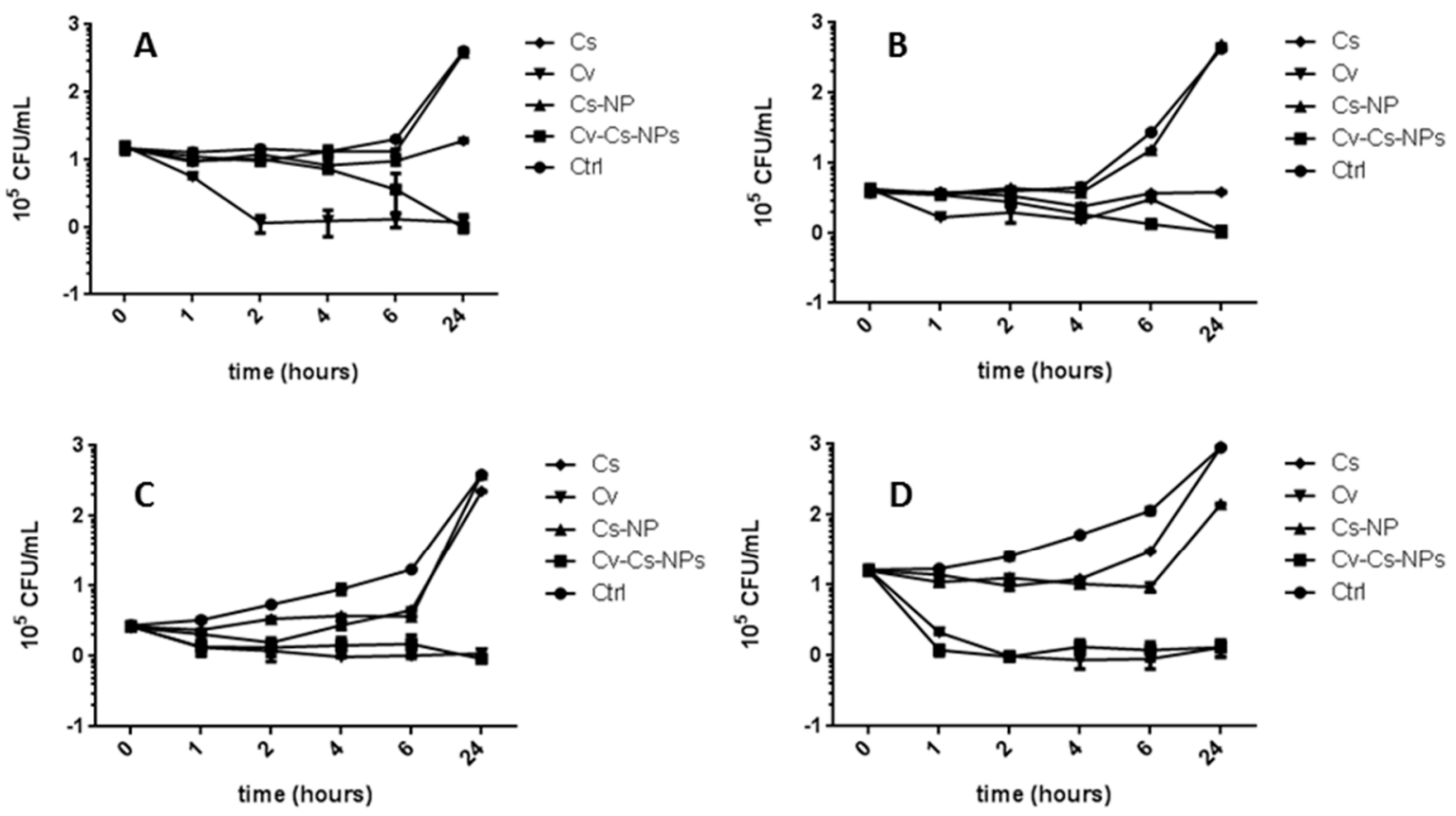

Figure 4. Time-killing curves of control (Ctrl), carvacrol loaded NPs (Cv-Cs-NPs), empty NPs (CsNPs), chitosan (Cs) and free carvacrol (Cv), against C. albicans (A), C. glabrata (B), C. krusei (C) and C. tropicalis (D) at different interval time. Values are reported as mean $\pm S E M, n=3$.

In all the cases free Cs and Cs-NPs were not able to kill the cells, at least the effect of free Cs was similar to the control for C. krusei (Figure 4C) and for C. tropicalis (Figure 4D) or resulted in a reduced growth for $C$. albicans (Figure $4 \mathrm{~A}$ ) and for C. glabrata (Figure 4B).

Conversely, in all the species considered, $\mathrm{Cv}-\mathrm{Cs}-\mathrm{NPs}$ and free $\mathrm{Cv}$, were able to kill the cells, but with different rates. In C. albicans (Figure 4A) Cv-Cs-NPs were able to inhibit cell viability after $6 \mathrm{~h}$ while free $\mathrm{Cv}$ exerted the same effect after $2 \mathrm{~h}$. In C. glabrata (Figure 4B) the killing effect of $\mathrm{Cv}-\mathrm{Cs}-\mathrm{NPs}$ is only evident after $24 \mathrm{~h}$ of incubation, the same time required for free $\mathrm{Cv}$ too. In C. krusei (Figure 4C) and in C. tropicalis (Figure 4D) the Cv-Cs-NPs were able to kill the cells after $2 \mathrm{~h}$ and $1 \mathrm{~h}$ respectively, similarly to free $\mathrm{Cv}$. These results show that the effects of free or loaded $\mathrm{Cv}$ are almost superimposable such in the case of $C$. glabrata, C. krusei and C. tropicalis, while only for C. albicans a difference in the time killing between free $\mathrm{Cv}$ and cargoed $\mathrm{Cv}$ is evident, indicating a gradual release of the monoterpene from NPs.

The differences observed in killing efficacy and kinetics, may strongly depend on the different distribution of polysaccharides within the cell wall of each Candida species as observed after treatments with different synthetic antifungal drugs [42-44], influencing both the interaction of chitosan NPs with the different cell wall architectures and the subsequent effects of the substances on the cells. 


\subsection{Inhibition on Pre-Formed and Forming Biofilm by Cv-Cs-NPs in Candida spp.}

To verify the possible inhibitor effect of $\mathrm{Cv}$-Cs-NPs on biofilm produced by different Candida species, we carried out XTT assays at beginning of biofilm formation and on pre-formed biofilms. Figure 5 reports the viability in presence of $\mathrm{Cv}-\mathrm{Cs}-\mathrm{NPs}, \mathrm{Cs}-\mathrm{NPs}, \mathrm{Cs}$ and free $\mathrm{Cv}$, at beginning of biofilm formation (A) and on pre-formed biofilm (B). As a result, $\mathrm{Cv}-\mathrm{Cs}-\mathrm{NPs}$ were able to inhibit biofilm formation at $30 \%$ and $40 \%$ in C. glabrata and in C. albicans respectively (Figure 5A), while in C. krusei and C. tropicalis (Figure 5A) inhibition on forming biofilm was around $90 \%$. It is surprisingly that the effect of Cs-NPs was almost superimposable to that due to $\mathrm{Cv}-\mathrm{Cs}-\mathrm{NPs}$, with only small differences in the case of C. krusei and C. tropicalis.

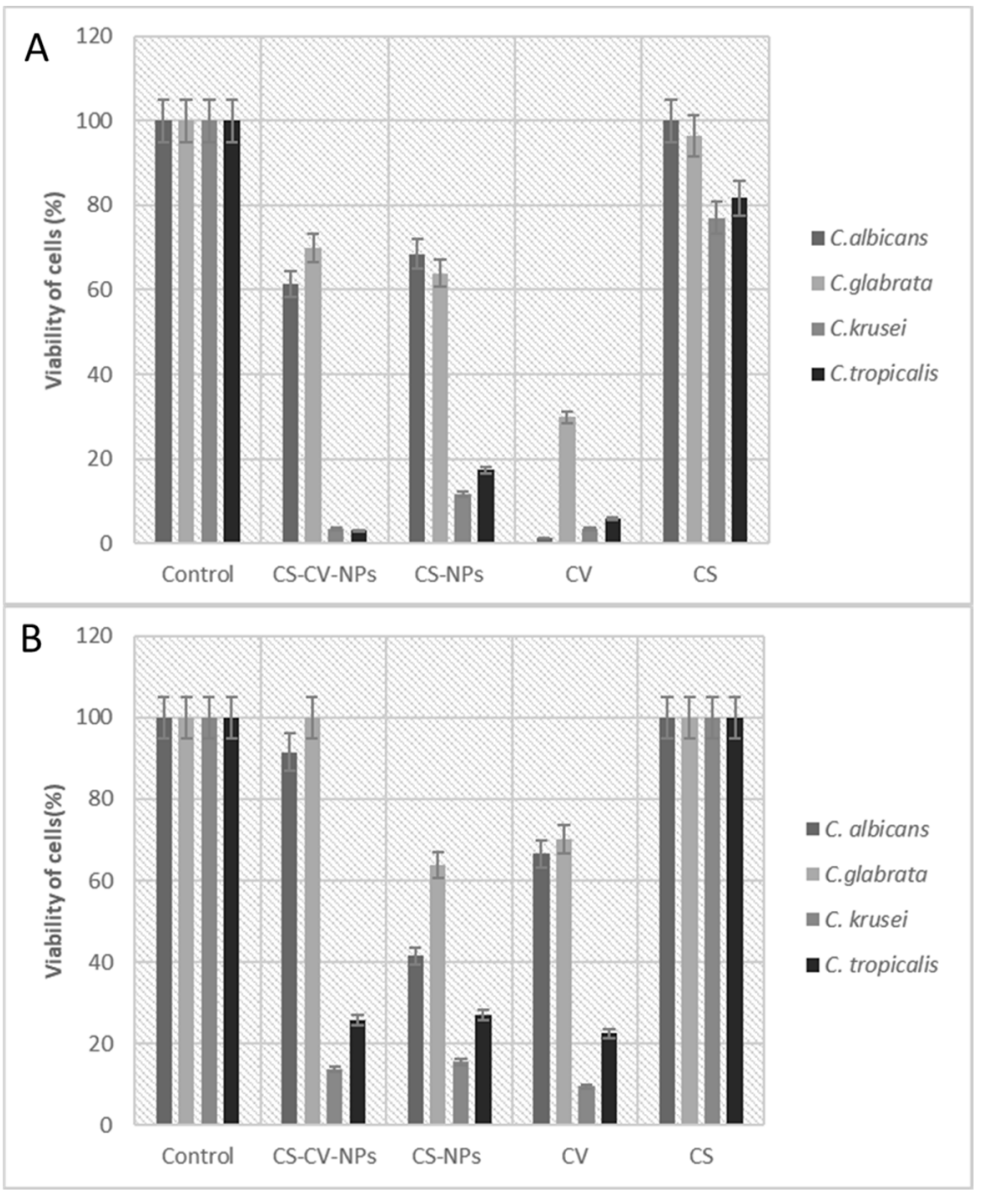

Figure 5. Cell viability expressed as \% of XTT reaction product read at $490 \mathrm{~nm}$. (A) NPs added at beginning of biofilm formation, (B) NPs added on preformed biofilm. Treated cells were compared to the control (one-way ANOVA followed by Dunnett's post hoc test, $p<0.05$ ).

On the other hand, free $\mathrm{Cv}$ differently inhibited forming and pre-forming biofilm depending on the strain considered. In preformed biofilm, it decreased the viability of about $70 \%$ in C. glabrata, while on C. albicans, C. krusei and C. tropicalis inhibition reached the $90 \%$. Similarly, on forming biofilm, Cv was more effective against C. krusei $(90 \%)$ and C. tropicalis $(70 \%)$, but in a lesser extent towards C. albicans and C. glabrata (around 30\% of inhibition).

Finally, Cs alone slightly inhibited biofilm formation in C. krusei and C. tropicalis ( $20 \%$ of effect), but no effect was visible on the other two species (Figure $5 \mathrm{~A}$ ); in the same manner no effect was detectable on preformed biofilm in all the strains (Figure 5B). It is also interesting to note that $\mathrm{Cs}$ alone in form of not aggregated polymer and in form of nanoparticle, behave differently. Cs-NPs despite the absence of $\mathrm{Cv}$, are effective in a similar manner to $\mathrm{Cv}-\mathrm{Cs}-\mathrm{NPs}$ and to free $\mathrm{Cv}$. This aspect may be explained considering that $\mathrm{Cs}$ 
is known to have an intrinsic antibiofilm activity [45-47], but the nanostructure of the NPs may enhance this feature being more effective in penetrating the complex biofilm network [48].

These results firstly suggest that $\mathrm{Cv}-\mathrm{Cs}-\mathrm{NPs}$ showed to be globally more efficient on C. tropicalis and C. krusei both on pre-formed and forming biofilms. But a similar effect is also due to unloaded Cs-NPs and to free $\mathrm{Cv}$ indicating that the encapsulation does not enhance $\mathrm{Cv}$ efficiency and that the effect is almost unspecific and not due to a synergistic or additive effect between $\mathrm{Cs}$ and $\mathrm{Cv}$.

Moreover, these data suggest that differences in biofilm structures among the considered species, may affect the response to NPs treatment observing that C. krusei and C. tropicalis biofilm seem more susceptible either in a pre-formed or in formation state. These differences may be dependent on the type of biofilm formation and structure.

It was observed that $C$. albicans mature biofilms exhibit a more heterogenous structure, composed by blastophores and hyphae surrounded by an extracellular material (ECM) of polysaccharide material [49]. In the case of C. glabrata, the biofilm is exclusively composed by yeast cells forming a multilayer and intimately packed structure or arranged in cell clusters [50]. In turn, C. tropicalis biofilm corresponds to a network of yeast, pseudohyphae and hyphae, with intense hyphal budding [51].

\section{Materials and Methods}

\subsection{Chemicals}

Na-Tripolyphosphate and chitosan (Cs) at ultra-low molecular weight Mw of $20 \mathrm{kDa}$ and a deacetylation degree of 95\% (Glentham Life Sciences, Corsham, UK) were used in this study. Carvacrol (density $0.98 \mathrm{~g} / \mathrm{mL}$ and PM $150.22 \mathrm{~g} / \mathrm{mol}$ ) and all other chemicals (ethanol, acetic acid, XTT, menadione) unless specified, were purchased from Sigma-Aldrich (Milan, Italy).

\subsection{Nanoparticles Preparation}

Chitosan-carvacrol nanoparticles were prepared as reported [33]. A $1.2 \% w / v$ chitosan solution was prepared by dissolving $1.2 \mathrm{~g}$ of chitosan in $100 \mathrm{~mL}$ of a $1 \% v / v$ aqueous acetic acid solution while stirring at room temperature overnight. The following day, Tween 60 $(0.7 \mathrm{~mL})$ was added to the chitosan solution and left to warm at $60^{\circ}$ for $2 \mathrm{~h}$ under continuous stirring to obtain a homogeneous solution. At the end of $2 \mathrm{~h}$, carvacrol was slowly added to the solution, leaving it to stir for $20 \mathrm{~min}$. In optimization experiments, increasing amounts of carvacrol, i.e., $0.12,0.24,0.36,0.48,0.60$ and $0.72 \mathrm{~g}$ were used to obtain different weight ratios of chitosan to $\mathrm{Cv}$ of 1:0.25; 1:0.50; $1: 0.75 ; 1: 1.0 ; 1: 1.25 ; 1: 1.50$ and $0.25: 1$ respectively. The solutions were divided into several aliquots, and carvacrol was added proportionally to the total volume. Next, a solution of TPP $(0.5 \% w / v 40 \mathrm{~mL})$ was slowly added to the O/A emulsion that was forming and left to stir for $30 \mathrm{~min}$. The final $\mathrm{pH}$ of the solution was 5.0. Finally, the particles were obtained by centrifugation at 10,000 rpm for $10 \mathrm{~min}$, after which the supernatant was removed from each sample and the resulting pellet washed with an aqueous solution of Tween $60(1 \% v / v)$ to remove free carvacrol. The same procedure was replicated to obtain carvacrol-free nanoparticles used as controls.

\subsection{Nanoparticles Characterization}

\subsubsection{Scanning Electron Microscopy (SEM)}

SEM analysis allowed the study of chitosan nanoparticle morphology. Samples were deposited on $12 \mathrm{~mm}$-diameter glass coverslips for $30 \mathrm{~min}$ and then were gold coated by sputtering (SCD 040 Balzers device, Bal-Tec). The samples were then examined with a scanning electron microscope FEI Quanta Inspect FEG, (FEI, Hillsboro, OR, USA) at $30 \mathrm{kV}$.

\subsubsection{Attenuated Total Reflectance Fourier-Transform Infrared Spectroscopy (ATR-FTIR)}

Spectra were acquired with a Spectrum One spectrophotometer (Perkin-Elmer, Milan, Italy) equipped with an ATR accessory having a ZnSe reflection element. The samples were 
solubilized in water by placing $3 \mu \mathrm{L}$ of $1 \mathrm{mg} / \mathrm{mL}$ solution on the crystal and left to air dry. Before sample analysis, an open beam background spectrum of a clean crystal was recorded; the spectra were acquired in Absorbance, between 4000 and $700 \mathrm{~cm}^{-1}$ after $40 \mathrm{scans}$ at a resolution of $1 \mathrm{~cm}^{-1}$. During the acquisitions at $25^{\circ} \mathrm{C}$, the crystal was continuously placed under nitrogen flow to remove residual water.

\subsubsection{Dynamic Light Scattering}

Nanoparticle size distribution and $\zeta$ potentials were obtained by DLS analysis performed with a Zetasizer Nano-S instrument (Malvern Instruments, Malvern, UK). Samples were dispersed in water obtaining a concentration of $1 \mathrm{mg} / \mathrm{mL}$ and centrifuged at $4000 \mathrm{rpm}$ for $5 \mathrm{~min}$ at $10^{\circ} \mathrm{C}$. The hydrodynamic diameter distribution of the samples was measured using protein refractive index (1.63) and water refractive index (1.33) as working parameters for the samples and solvent, respectively. Size results were reported as the $\mathrm{Z}$ average of the particle hydrodynamic diameter distribution of three measurements at $25^{\circ} \mathrm{C}$ of at least 10 runs repeated three times.

\subsubsection{Evaluation of Encapsulation Efficiency and Loading Capacity}

Nanoparticle's preparations $(200 \mu \mathrm{L})$ after an ultrafiltration step employing $30 \mathrm{kDa}$ MW cut off filters to eliminate free carvacrol, were mixed with aqueous hydrochloric acid solution $(2 \mathrm{~N})$ for a final volume of $2 \mathrm{~mL}$ and boiled at $95^{\circ} \mathrm{C}$ for $30 \mathrm{~min}$. After cooling down, ethanol $(1 \mathrm{~mL})$ was subsequently added to the mixture. A blank solution was similarly prepared replacing the sample dispersion with ultrapure water. After centrifugation at $10,000 \mathrm{rpm}$ for $5 \mathrm{~min}$ at $25^{\circ} \mathrm{C}$, the supernatant was collected and analyzed by a spectrophotometer at wavelengths ranging from $278 \mathrm{~nm}$. The encapsulation efficiency (EE) and loading capacity (LC) of carvacrol were calculated from Equations (1) and (2), respectively:

$$
\begin{gathered}
\% \mathrm{EE}=\text { mass of loaded carvacrol } / \text { mass of initial carvacrol } \times 100 \\
\% \mathrm{LC}=\text { mass of loaded carvacrol } / \text { mass of sample } \times 100
\end{gathered}
$$

\subsection{Release Kinetics}

The release kinetics of $\mathrm{Cv}$ from the chitosan particles were analyzed in phosphate buffered saline (PBS), the same used for the biological assays. The pellet of free and loaded nanoparticles was resuspended in $0.8 \mathrm{~mL}$ of PBS. The mixture was then left in gentle agitation for the required time at $25^{\circ} \mathrm{C}$. At different intervals of incubation time $(0 \mathrm{~h}$, $24 \mathrm{~h}, 48 \mathrm{~h}, 72 \mathrm{~h}$, and $96 \mathrm{~h}$ ), $100 \mu \mathrm{L}$ of the sample was taken, centrifuged at $9000 \mathrm{rpm}$ for $5 \mathrm{~min}$ at $25^{\circ} \mathrm{C}$. An equal volume of PBS was then added to the solution to restore the original volume. The amount of carvacrol released into the supernatant was calculated by UV spectrophotometer considering the maximum absorption wavelength of carvacrol $(278 \mathrm{~nm})$. The spectrum and concentrations of carvacrol were determined by UV-Vis Spectrophotometer (8453 UV-Vis Supplies, Agilent Technologies, Santa Clara, CA, USA) by diluting the compound in ethanol. The calculated molar extinction coefficient for carvacrol in ethanol was $2.650 \mathrm{M}^{-1} \mathrm{~cm}^{-1}$.

\subsection{Organisms and Growth Conditions}

Candida spp. strains from clinical isolates were used through the study. In particular, the strains were C. albicans AIDS 68, C. glabrata SFY115, C. tropicalis 47829 and C. krusei 45709. Each strain was routinely maintained on Sabouraud dextrose agar medium (SDA; Difco, Detroit, MI, USA) at $28^{\circ} \mathrm{C}$.

\subsection{Evaluation of Antimicrobial Activity}

The antimicrobial activity of the chitosan-carvacrol nanoparticles (Cv-Cs-NPs), chitosan nanoparticles (Cs-NPs), chitosan (Cs) and carvacrol (Cv) were evaluated by a microbroth dilution method according to Clinical and Laboratory Standards Institute (CLSI), Approved Standard M27-A3, 2008. The minimal inhibitory concentration (MIC) was deter- 
mined as the lowest concentration of $\mathrm{Cv}-\mathrm{Cs}-\mathrm{NPs}, \mathrm{Cs}-\mathrm{NPs}, \mathrm{Cs}$ or $\mathrm{Cv}$ at which no microbial growth was observed, and were tested against four clinical isolates of Candida spp. Cv-CsNPs, Cs-NPs, Cs and Cv were diluted in RPMI 1640 supplemented with MOPS and Tween 20 (final concentration of $0.01 \% \mathrm{v} / \mathrm{v}$ ). The dilutions ranging from 0.006 to $1.56 \mathrm{mg} / \mathrm{mL}$. The inoculum size was about $2.5 \times 10^{3}$ cells $/ \mathrm{mL}$. The plates were incubated at $28^{\circ} \mathrm{C}$ for 24-48 h.

\subsection{In Vitro Time-Kill Kinetics}

Time-kill curve methods were used to evaluate the activities of $\mathrm{Cv}-\mathrm{Cs}-\mathrm{NPs}, \mathrm{Cs}-\mathrm{NPs}$, $\mathrm{Cs}$ or $\mathrm{Cv}$ against different Candida spp. An overnight broth culture of Candida spp. was diluted in Sabouraud broth to obtain a starting inoculum of about $1 \times 10^{5} \mathrm{CFU} / \mathrm{mL}$. Substances were added to the broth culture at concentrations of MIC. $100 \mu \mathrm{L}$ aliquots of broth were taken after 0, 30, 60, 120, $360 \mathrm{~min}$ and $24 \mathrm{~h}$ of incubation. Each aliquot was serially diluted, plated onto Sabouraud agar plates in duplicates and incubated at $28{ }^{\circ} \mathrm{C}$ to $48 \mathrm{~h}$. The number of colony forming units was counted and CFU $/ \mathrm{mL}$ was determined. The values were plotted to obtain the kinetics of killing. Results are expressed as CFU/mL.

\subsection{Biofilm Formation}

Biofilm formation was tested in presterilized polystyrene flat-bottom 96-well microtiter plates (Corning, Corning, NY, USA). A Candida spp. cell suspension $\left(1 \times 10^{6}\right.$ cells $\left./ \mathrm{mL}\right)$, at grown, was incubated for $48 \mathrm{~h}$ at $37^{\circ} \mathrm{C}$. After $3 \mathrm{~h}$ or $24 \mathrm{~h}$ of biofilm formation, $\mathrm{Cv}-\mathrm{Cs}-$ NPs, Cs-NPs, Cs or Cv at their respective MIC concentrations, were added. After $24 \mathrm{~h}$ a semi quantitative measurement of biofilm formation was made by using an XTT[2,3-bis(2methoxy-4-nitro-5-sulfo-phenyl)-2H-tetra-zolium-5-carboxanilide]-reduction assay [52] XTT was dissolved in PBS at $0.5 \mathrm{~g} / \mathrm{L}$. The solution was sterilized through a $0.22 \mu \mathrm{m}$ pore size filter. Prior to each assay, the XTT solution was thawed and supplemented with menadione $(10 \mathrm{mM}$ stock dissolved in acetone to a final concentration $1 \mu \mathrm{M})$. An aliquot of $1 \mathrm{~mL}$ of the XTT-menadione solution was added per well, and the plates were incubated for 2 hat $37^{\circ} \mathrm{C}$. A sample $(500 \mu \mathrm{L})$ was then transferred from each well into a fresh 12 -well plate (to eliminate interference of cells with colorimetric readings) and the colorimetric change, resulting from XTT reduction, was measured at $490 \mathrm{~nm}$.

\subsection{Statistical Analysis}

Statistical analysis was performed by GraphPad Prism (version 5.0, GraphPad Software Inc., San Diego, CA, USA) by using one way ANOVA followed by Dunnett's post hoc test. $(p<0.05)$.

\section{Conclusions}

In this study, chitosan nanoparticles produced by means of an ionic gelation method were loaded with the phenolic monoterpene carvacrol. From a bioassay guided optimization, the best formulation of $1: 1.5 \mathrm{Cs} / \mathrm{Cv}(w / w)$ was characterized by means of FTIR, UV spectroscopy and DLS, and tested against four different clinical isolated strains of Candida spp. represented among the most known pathogenic species: C. albicans AIDS 68, C. glabrata SFY115, C. tropicalis 47829 and C. krusei 45709. The antimicrobial activity, the time killing, and the inhibition of cells organized in the biofilm at the initial stage and as an established form have been evaluated.

The Cv-Cs-NPs showed to possess a better antifungal effect compared to free $\mathrm{Cv}$ being more effective against C. albicans strain with a MIC of $24 \mu \mathrm{g} / \mathrm{mL}$, and were also able to affect viability of cells in the pre-formed and forming biofilm, although in this case, similar effects could be also observed upon treatment with Cs-NPs and free Cv.

An evident species-specific relationship could be observed regarding the effect of free and loaded Cs-NPs, highlighting the different structural organization existing among the tested species and between the planktonic and biofilm forms suggesting that at least in the 
case of Candida, a more refined optimization of the production of antibiofilm $\mathrm{Cv}-\mathrm{Cs}-\mathrm{NPs}$ should be carried out in relation to the target species.

Author Contributions: Conceptualization, L.A., A.S., A.V. and M.C.; methodology, L.A., A.S., A.M., A.V. and M.C.; validation, L.A., A.S., A.V. and M.C., formal analysis, L.A. and A.V.; investigation, L.A., A.S., A.V., A.M. and M.C.; resources, L.A., A.S., A.V. and M.C.; data curation, L.A., A.S., A.V., A.M. and M.C.; writing—original draft preparation, A.V. and L.A.; writing-review and editing, L.A., A.S., A.V., A.M. and M.C.; supervision, L.A., A.S., A.V. and M.C. All authors have read and agreed to the published version of the manuscript.

Funding: This research was partially funded by Istituto Superiore di Sanità, ISS (Ministry of HealthISS funding).

Institutional Review Board Statement: Not applicable.

Informed Consent Statement: Not applicable.

Data Availability Statement: Not applicable.

Acknowledgments: The authors want to acknowledge "Cooperativa gruppo Comunale logistica industriale integrata. Soc. Coop." for its support.

Conflicts of Interest: The authors declare no conflict of interest.

\section{References}

1. Kapustová, M.; Puškárová, A.; Bučková, M.; Granata, G.; Napoli, E.; Annušová, A.; Mesárošová, M.; Kozics, K.; Pangallo, D.; Geraci, C. Biofilm inhibition by biocompatible poly( $\varepsilon$-caprolactone) nanocapsules loaded with essential oils and their cyto/genotoxicity to human keratinocyte cell line. Int. J. Pharm. 2021, 606, 120846. [CrossRef] [PubMed]

2. De Mastro, G.; Tarraf, W.; Verdini, L.; Brunetti, G.; Ruta, C. Essential oil diversity of Origanum vulgare L. populations from Southern Italy. Food Chem. 2017, 235, 1-6. [CrossRef] [PubMed]

3. Friedman, M. Chemistry and multibeneficial bioactivities of carvacrol (4-isopropyl-2-methylphenol), a component of essential oils produced by aromatic plants and spices. J. Agric. Food Chem. 2014, 62, 7652-7670. [CrossRef]

4. Beena, S.; Kumar, D.; Rawat, D.S. Synthesis and antioxidant activity of thymol and carvacrol based Schiff bases. Bioorg. Med. Chem. Lett. 2013, 23, 641-645. [CrossRef]

5. Pellegrini, M.; Ricci, A.; Serio, A.; Chaves-López, C.; Mazzarrino, G.; D'Amato, S.; Lo Sterzo, C.; Paparella, A. Characterization of Essential Oils Obtained from Abruzzo Autochthonous Plants: Antioxidant and Antimicrobial Activities Assessment for Food Application. Foods 2018, 7, 19. [CrossRef]

6. Hosseini, S.S.; Yadegari, M.H.; Rajabibazl, M.; Ghaemi, E.A. Inhibitory effects of carvacrol on the expression of secreted aspartyl proteinases 1-3 in fluconazole-resistant Candida albicans isolates. Iran. J. Microbiol. 2016, 8, 401-409.

7. Shaban, S.; Patel, M.; Ahmad, A. Improved efficacy of antifungal drugs in combination with monoterpene phenols against Candida auris. Sci. Rep. 2020, 10, 1162. [CrossRef]

8. Khosravi, A.R.; Shokri, H.; Fahimirad, S. Efficacy of medicinal essential oils against pathogenic Malassezia sp. isolates. J. Mycol. Med. 2016, 26, 28-34. [CrossRef] [PubMed]

9. Vinciguerra, V.; Rojas, F.; Tedesco, V.; Giusiano, G.; Angiolella, L. Chemical characterization and antifungal activity of Origanum vulgare, Thymus vulgaris essential oils and carvacrol against Malassezia furfur. Nat. Prod. Res. 2019, 33, 3273-3277. [CrossRef]

10. Niu, C.; Wang, C.; Yang, Y.; Chen, R.; Zhang, J.; Chen, H.; Zhuge, Y.; Li, J.; Cheng, J.; Xu, K.; et al. Carvacrol induces Candida albicans apoptosis associated with $\mathrm{Ca}^{2+}$ /calcineurin pathway. Front. Cell. Infect. Microbiol. 2020, 10, 192. [CrossRef]

11. Llana-Ruiz-Cabello, M.; Gutiérrez-Praena, D.; Pichardo, S.; Moreno, F.J.; Bermúdez, J.M.; Aucejo, S.; Cameán, A.M. Cytotoxicity and morphological effects induced by carvacrol and thymol on the human cell line Caco-2. Food Chem. Toxicol. 2014, 64, 281-290. [CrossRef]

12. Tavares, A.G.; Andrade, J.; Resende, R.; Silva, A.; Suprani Marques, C.; Ramos da Silva, J.O.; Dantas Vanetti, M.C.; Ramos de Melo, N.; de Fátima Ferreira Soar, N. Carvacrol-loaded liposome suspension: Optimization, characterization and incorporation into poly(vinyl alcohol) films. Food Funct. 2021, 12, 6549-6557. [CrossRef] [PubMed]

13. Shakeri, F.; Shakeri, S.; Hojjatoleslami, M. Preparation and characterization of carvacrol loaded polyhydroxybutyrate nanoparticles by nanoprecipitation and dialysis methods. J. Food Sci. 2014, 79, N697-N705. [CrossRef] [PubMed]

14. Guarda, A.; Rubilar, J.F.; Miltz, J.; Galotto, M.J. The antimicrobial activity of microencapsulated thymol and carvacrol. Int. J. Food Microbiol. 2011, 146, 144-150. [CrossRef] [PubMed]

15. Iannitelli, A.; Grande, R.; Di Stefano, A.; Di Giulio, M.; Sozio, P.; Bessa, L.J.; Laserra, S.; Paolini, C.; Protasi, F.; Cellini, L. Potential antibacterial activity of carvacrol-loaded poly(DL-lactide-co-glycolide) (PLGA) nanoparticles against microbial biofilm. Int. J. Mol. Sci. 2011, 12, 5039-5051. [CrossRef] [PubMed] 
16. Owen, L.; Webb, J.P.; Green, J.; Smith, L.J.; Laird, K. From formulation to in vivo model: A comprehensive study of a synergistic relationship between vancomycin, carvacrol, and cuminaldehyde against Enterococcus faecium. Phytother. Res. 2020, 34, 1638-1649. [CrossRef]

17. Tripathy, A.; Pahal, S.; Mudakavi, R.J.; Raichur, A.M.; Varma, M.M.; Sen, P. Impact of Bioinspired Nanotopography on the Antibacterial and Antibiofilm Efficacy of Chitosan. Biomacromolecules 2018, 19, 1340-1346. [CrossRef] [PubMed]

18. Je, H.J.; Kim, E.S.; Lee, J.S.; Lee, H.G. Release Properties and cellular uptake in Caco-2 cells of size-controlled chitosan nanoparticles. J. Agric. Food Chem. 2017, 65, 10899-10906. [CrossRef]

19. Nagpal, K.; Singh, S.K.; Mishra, D.N. Chitosan nanoparticles: A promising system in novel drug delivery. Chem. Pharm. Bull. 2010, 58, 1423-1430. [CrossRef]

20. Garg, U.; Chauhan, S.; Nagaich, U.; Jain, N. Current advances in chitosan nanoparticles based drug delivery and targeting. Adv. Pharm. Bull. 2019, 9, 195-204. [CrossRef]

21. Yang, Y.; Li, N.; Wang, T.M.; Di, L. Natural Products with Activity against Lung Cancer: A Review Focusing on the Tumor Microenvironment. Int. J. Mol. Sci. 2021, 22, 10827. [CrossRef]

22. Rizeq, B.R.; Younes, N.N.; Rasool, K.; Nasrallah, G.K. Synthesis, bioapplications, and toxicity evaluation of chitosan-based nanoparticles. Int. J. Mol. Sci. 2019, 20, 5776. [CrossRef] [PubMed]

23. Divya, K.; Jisha, M.S. Chitosan nanoparticles preparation and applications. Environ. Chem. Lett. 2018, 16, 101-112. [CrossRef]

24. Kulikov, S.N.; Lisovskaya, S.A.; Zelenikhin, P.V.; Bezrodnykh, E.A.; Shakirova, D.R.; Blagodatskikh, I.V.; Tikhonov, V.E. Antifungal activity of oligochitosans (short chain chitosans) against some Candida species and clinical isolates of Candida albicans: Molecular weight-activity relationship. Eur. J. Med. Chem. 2014, 74, 169-178. [CrossRef] [PubMed]

25. Barbos, M.; Vale, N.; Costa, F.M.T.A.; Martins, M.C.L.; Gomes, P. Tethering antimicrobial peptides onto chitosan: Optimization of azide-alkyne "click" reaction conditions. Carbohydr. Polym. 2017, 165, 384-393. [CrossRef]

26. Layek, B.; Lipp, L.; Singh, J. Cell Penetrating Peptide Conjugated Chitosan for Enhanced Delivery of Nucleic Acid. Int. J. Mol. Sci. 2015, 16, 28912-28930. [CrossRef] [PubMed]

27. El-Sayed, N.S.; Shirazi, A.N.; El-Meligy, M.G.; El-Ziaty, A.K.; Nagieb, Z.A.; Parang, K.; Tiwari, R.K. Design, synthesis, and evaluation of chitosan conjugated GGRGDSK peptides as a cancer cell-targeting molecular transporter. Int. J. Biol. Macromol. 2016, 87, 611-622. [CrossRef]

28. Wisplinghoff, H.; Ebbers, J.; Geurtz, L.; Stefanik, D.; Major, Y.; Edmond, M.B.; Wenzel, R.P.; Seifert, H. Nosocomial bloodstream infections due to Candida spp. in the USA: Species distribution, clinical features and antifungal susceptibilities. Int. J. Antimicrob. Agents 2014, 43, 78-81. [CrossRef]

29. Gulati, M.; Nobile, C.J. Candida albicans biofilms: Development, regulation, and molecular mechanisms. Microbes Infect. 2016, 18, 310-321. [CrossRef]

30. Cavalheiro, M.; Teixeira, M.C. Candida Biofilms: Threats, Challenges, and Promising Strategies. Front. Med. 2018, 5, 28. [CrossRef]

31. Lin, L.; Zhu, Y.; Thangaraj, B.; Abdel-Samie, M.A.S.; Cui, H. Improving the stability of thyme essential oil solid liposome by using $\beta$-cyclodextrin as a cryoprotectant. Carbohydr. Polym. 2018, 188, 243-251. [CrossRef] [PubMed]

32. Bell, I.R.; Ives, J.A.; Jonas, W.B. Nonlinear effects of nanoparticles: Biological variability from hormetic doses, small particle sizes, and dynamic adaptive interactions. Dose Response 2013, 12, 202-232. [CrossRef] [PubMed]

33. Keawchaoon, L.; Rangrong, Y. Preparation, characterization and in vitro release study of carvacrol-loaded chitosan nanoparticles. Colloids Surf. B Biointerfaces 2011, 84, 163-171. [CrossRef] [PubMed]

34. Rostami, E.; Kashanian, S.; Askari, M. The effect of ultrasound waves on levothyroxine release from chitosan nanoparticles. Adv. Mater. Res. 2014, 829, 284-288. [CrossRef]

35. Alarfaj, J. Preparation, Characterization and Antibacterial Effect of Chitosan Nanoparticles against Food Spoilage Bacteria. Pure Appl. Microbiol. 2019, 13, 1273-1278. [CrossRef]

36. Kim, E.S.; Kim, D.Y.; Lee, J.S.; Lee, H.G. Quercetin delivery characteristics of chitosan nanoparticles prepared with different molecular weight polyanion cross-linkers. Carbohydr. Polym. 2021, 267, 118157. [CrossRef]

37. Woranuch, S.; Yoksan, R. Preparation, characterization and antioxidant property of water-soluble ferulic acid grafted chitosan. Carbohydr. Polym. 2013, 96, 495-502. [CrossRef]

38. Nallamuthua, I.; Devib, A.; Khanuma, F. Chlorogenic acid loaded chitosan nanoparticles with sustained release property, retained antioxidant activity and enhanced bioavailability. Asian J. Pharm. Sci. 2015, 10, 203-211. [CrossRef]

39. Agnihotri, S.A.; Mallikarjuna, N.N.; Aminabhavi, T.M. Recent advances on chitosan-based micro- and nanoparticles in drug delivery. J. Control. Release 2004, 100, 5-28. [CrossRef]

40. Sobhani, Z.; Mohammadi Samani, S.; Montaseri, H.; Khezri, E. Nanoparticles of chitosan loaded ciprofloxacin: Fabrication and antimicrobial activity. Adv. Pharm. Bull. 2017, 7, 427-432. [CrossRef]

41. Mussin, J.; Robles-Botero, V.; Casañas-Pimentel, R.; Rojas, F.; Angiolella, L.; San Martín-Martínez, E.; Giusiano, G. Antimicrobial and cytotoxic activity of green synthesis silver nanoparticles targeting skin and soft tissue infectious agents. Sci. Rep. 2021, 11, 14566. [CrossRef]

42. Walker, L.A.; Munro, C.A. Spongin induced cell wall changes of Candida species influences macrophage interactions. Front. Cell. Infect. Microbiol. 2020, 10, 164. [CrossRef] 
43. Angiolella, L.; Maras, B.; Stringaro, A.R.; Arancia, G.; Mondello, F.; Girolamo, A.; Palamara, A.T.; Cassone, A. Glucan-associated protein modulations and ultrastructural changes of the cell wall in Candida albicans treated with micafungin, a water-soluble, lipopeptide antimycotic. J. Chemother. 2005, 4, 409-416. [CrossRef] [PubMed]

44. Stringaro, A.; Vavala, E.; Colone, M.; Pepi, F.; Mignogna, G.; Garzoli, S.; Cecchetti, S.; Ragno, R.; Angiolella, L. Effects of Mentha suaveolens Essential Oil Alone or in Combination with Other Drugs in Candida albicans. Evid.-Based Complement. Altern. Med. 2014, 2014, 125904. [CrossRef] [PubMed]

45. Martinez, L.R.; Radu Mihu, M.; Tar, M.; Cordero, R.J.B.; Han, G.; Friedman, A.J.; Friedman, J.M.; Nosanchuk, J.D. Demonstration of antibiofilm and antifungal efficacy of chitosan against Candidal biofilms, using an in vivo central venous catheter model. J. Infect. Dis. 2010, 201, 1436-1440. [CrossRef] [PubMed]

46. Carlson, R.P.; Taffs, R.; Davison, W.M.; Stewart, P.S. Anti-biofilm properties of chitosan-coated surfaces. J. Biomater. Sci. Polym. Ed. 2008, 19, 1035-1046. [CrossRef] [PubMed]

47. Felipe, V.; Breser, M.L.; Bohl, L.P.; Rodrigues da Silva, E.; Morgante, C.A.; Correa, S.G.; Porporatto, C. Chitosan disrupts biofilm formation and promotes biofilm eradication in Staphylococcus species isolated from bovine mastitis. Int. J. Biol. Macromol. 2019, 126, 60-67. [CrossRef]

48. Velino, C.; Carella, F.; Adamiano, A.; Sanguinetti, M.; Vitali, A.; Catalucci, D.; Bugli, F.; Iafisco, M. Nanomedicine Approaches for the Pulmonary Treatment of Cystic Fibrosis. Front. Bioeng. Biotechnol. 2019, 7, 406. [CrossRef]

49. Chandra, J.; Kuhn, D.M.; Mukherjee, P.K.; Hoyer, L.L.; McCormick, T.; Ghannoum, M.A. Biofilm formation by the fungal pathogen Candida albicans: Development, architecture, and drug resistance. J. Bacteriol. 2001, 183, 5385-5394. [CrossRef] [PubMed]

50. Silva, S.; Henriques, M.; Martins, A.; Oliveira, R.; Williams, D.; Azeredo, J. Biofilms of non-Candida albicans Candida species: Quantification, structure and matrix composition. Med. Mycol. 2009, 47, 681-689. [CrossRef]

51. Bizerra, F.C.; Nakamura, C.V.; de Poersch, C.; Estivalet Svidzinski, T.I.; Borsato Quesada, R.M.; Goldenberg, S.; Krieger, M.A.; Yamada-Ogatta, S.F. Characteristics of biofilm formation by Candida tropicalis and antifungal resistance. FEMS Yeast Res. 2008, 8 , 442-450. [CrossRef] [PubMed]

52. Ramage, G.; Vande Walle, K.; Wickes, B.L.; López-Ribot, J.L. Standardized method for in vitro antifungal susceptibility testing of Candida albicans biofilms. Antimicrob. Agents Chemother. 2001, 45, 2475-2479. [CrossRef] [PubMed] 